\title{
Experimental study of hemodynamics in the circle of willis
}

\author{
Guangyu Zhu ${ }^{1+}$, Qi Yuan ${ }^{1 *+}$, Jian Yang ${ }^{2}$, Joon Hock Yeo ${ }^{3}$
}

\author{
* Correspondence: qyuan@mail. \\ xjtu.edu.cn \\ ${ }^{1}$ School of Energy and Power \\ Engineering, Xi'an Jiaotong \\ University, Xi'an, 710049, Shaanxi, \\ China
}

\begin{abstract}
Background: The Circle of Willis (CoW) is an important collateral pathway of the cerebral blood flow. An experimental study of the cerebral blood flow (CBF) distribution in different anatomical variations may help to a better understanding of the collateral mechanism of the CoW.

Methods: An in-vitro test rig was developed to simulate the physiological cerebral blood flow in the CoW. Ten anatomical variations were considered in this study, include a set of different degrees of stenosis in L-ICA and L-ICA occlusion coexist with common anatomical variations. Volume flow rates of efferent arteries and pressure signals at the end of communicating arteries of each case were recorded. Physiological pressure waveforms were applied as inlet boundary condition.

Results: In the development of L-ICA stenosis, the total CBF decreases with the increase of stenosis degree. The blood supply of ipsilateral middle cerebral artery (MCA) was affected most by the stenosis of L-ICA. Anterior communicating artery (ACOA) and ipsilateral posterior communicating artery (PCOA) function as important collateral pathways of cerebral collateral circulation when unilateral stenosis occurred. The blood supply of anterior cerebral circulation was compensated by the posterior cerebral circulation through ipsilateral PCOA when L-ICA stenosis degree is greater than $40 \%$ and the affected side was compensated immediately by the unaffected side through ACoA. Blood flow of the anterior circulation and the total CBF reached the minimum among all cases studied when L-ICA occlusion coexist with the absence of PCOA.

Conclusion: The results demonstrated the flow distribution patterns of the CoW under anatomical variations and clarified the collateral mechanism of the CoW. The flow ACoA is the most sensitive indexes to the morphology change of ipsilateral ICA. The relative independence of the circulation in anterior and posterior sections of the CoW is not broken and the function of ipsilateral PCOA is not activated until a severe stenosis of unilateral ICA occurs. PCOA is the most important collateral pathway of the collateral circulation and the missing of PCOA has the highest risk of stroke when the ipsilateral ICA has severe stenosis. These findings may provide the basis for future therapeutic and diagnosis applications.
\end{abstract}

\section{Background}

The Circle of Willis (CoW) is a ring like artery structure located at the bottom of brain. This structure provides important collateral circulation paths to maintain the sufficient blood supply, especially when stenosis or surgical clamping of the cerebral arteries happens. These collaterals consist of cross-flow through the anterior communicating artery toward the ipsilateral sphere of the ICA lesion, posterior to anterior flow through the ipsilateral posterior communicating artery, or both these systems [1-4].

C 2015 Zhu et al: licensee BioMed Central Ltd. This is an Open Access article distributed under the terms of the Creative Commons Attribution License (http://creativecommons.org/licenses/by/4.0), which permits unrestricted use, distribution, and reproduction in any medium, provided the original work is properly cited. The Creative Commons Public Domain Dedication waiver (http:// creativecommons.org/publicdomain/zero/1.0/) applies to the data made available in this article, unless otherwise stated. 
Unfortunately, congenital incompleteness of $\mathrm{CoW}$, such as the lack of anterior communicating artery, unilateral or bilateral PCoA, is found in $50 \%-60 \%$ of the population [5-7]. Other anatomical variations, including fused vessels, string-like vessels and the presence of extra vessels, are also not uncommon (Figure 1)[8]. Such variations undermine the compensational capability of the artery, and can cause undesirable clinical consequences, including ischemia stroke and transient ischemia attack (TIA). When either anatomical variations coexist with ICA stenosis or surgical clamping, the risk would be even higher. Therefore, it is important to be able to assess the blood distribution and collateral flow patterns of the CoW under various anatomical and pathological situations to help understanding the mechanism of stroke, planning the clinical surgery and diagnosis of early stage stroke.

In the literature, there are many papers proposing various methods for identifying the collateral flow patterns in complete and incomplete CoW. Clinically, the using of Transcranial Doppler (TCD) [9-20], Magnetic Resonance Angiography (MRA) [13,15,17,19,21-26] and Computed Tomography Angiography (CTA)[22,27-29] provide the in-vivo perspective of the role of the $\mathrm{CoW}$ in the collateral flow in anatomical variations. Numerically, one-dimensional [30-36], two-dimensional [37,38] and threedimensional $[31,34,39-43]$ models of the CoW were developed, flows in the CoW with common anatomical variations were investigated.

In contrast to a host of clinical and numerical studies, however, only limited in-vitro experimental studies were reported in open literature. Cieslicki et al [44] carried out invitro investigation of flow distribution in the CoW under four extreme cases, including complete CoW, unilateral ICA occlusion, complete occlusion of the vertebral-basilar system and bilateral ICA occlusion. Fahy et al [45] observed the flow distribution in three different patient specific model of $\mathrm{CoW}$ and assessed the risk factor brought by anatomical variations, including missing of unilateral PCoA, unilateral pre-communicating part of the

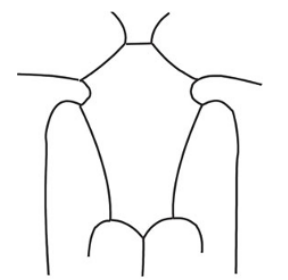

Complete CoW $(49 \%)$

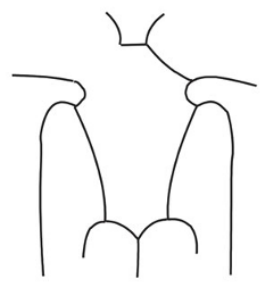

ACA, A1

$(6 \%)$

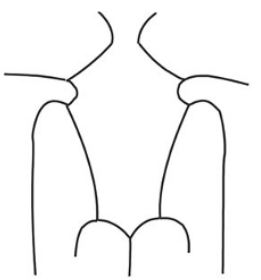

$\mathrm{ACoA}$

$(1 \%)$

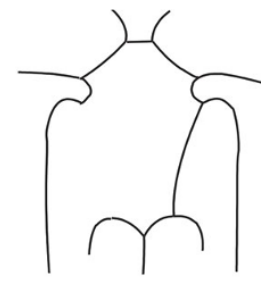

PCoA

$(9 \%)$

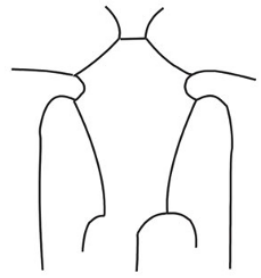

PCA, P1

$(9 \%)$

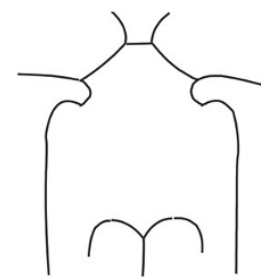

PCoAs

$(9 \%)$

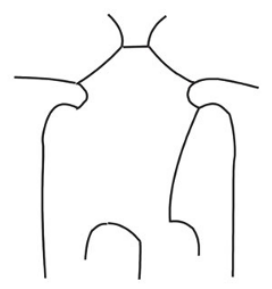

PCoA \& contralateral

PCA, P1 (9\%)

Figure 1 Some common variations of the Circle of Willis [48]. 
posterior cerebral artery, unilateral pre-communicating part of the anterior cerebral artery, bilateral PCoAs. In addition to limited quantity, there is a lack of in-vitro investigation that reveals the flow distribution in the development of ICA stenosis and ICA occlusion coexist with anatomical variations.

Moreover, details of the collateral mechanism of complete circle and incomplete circle are remaining debatable. Conflicting results have been reported on the flow patterns in the communicating arteries and importance of the collateral pathways. For the complete CoW, some in-vitro [46] and in-vivo [17] studies mentioned there are no flow across ACoA in a complete CoW, this phenomenon was also supported by numerical simulations [32,33,47]; Other numerical $[48,49]$ and in-vitro [45] studies, in contrast, suggested flow across ACoA observed in complete circle of Willis under symmetrical boundary conditions. When unilateral ICA stenosis or occlusion occurred, Hartamp et al.[50], Miralles et al.[51] and Hoksbergen et al. [16] concluded that ACoA plays a more important role than PCoA in patients with severe ICA stenosis; Results from other studies suggested the fetal type or missing of ipsilateral PCoA is the only risk factor for ischemic cerebral symbols $[4,38,51]$.

Motivated by the lacking of extensive in-vitro experimental studies and the conflicting research findings, an in-vitro experimental study focus on the collateral flow patterns in the CoW was carried out. A series of different degree of stenosis in unilateral ICA and unilateral ICA occlusion coexist with anatomical variations were simulated in this study. The CBF distributions in efferent arteries, cross flow in communicating arteries and collateral circulation mechanism of the CoW were investigated.

\section{Methods}

\section{Model preparation}

In previous studies, various techniques were used to measure the geometry of the CoW, including CTA imaging, MRI and direct measure of cerebral vessels. Due to individual differences, the dimensions of each artery segment are varied from case to case. In this study, average length and diameter from previous studies were used in this study to achieve a universal model $[33,36,44,47,52]$. The dimensions of each segment are listed in Table 1 and a physical model based on these dimensions was constructed. To simplify the model, each vessel is represented by a single silicon tube of constant radius. This simplification is acceptable because the length of every segment is relatively short and the conicity index is relatively small at cerebral artery site.

To simulate the different degrees of ICA stenosis, a set of connectors with different flow tunnel diameter was prepared. All connectors were made by copper cylinders of a length of $20 \mathrm{~mm}$ and an outer diameter of $4.5 \mathrm{~mm}$. Flow tunnels with different diameters were drilled at the centre of the cross section along the axial direction to simulate different degrees of stenosis of ICA. The degree of stenosis is defined as the ratio of inner diameter of stenosed artery over original inner diameter. L-ICA occlusion was simulated by clamping the tube using a hemostat.

\section{Physiological flow system}

The schematic diagram of the patented (ZL 200910021375.5) test rig is shown in Figure 2. A linear actuator (LMS 50, PBA System Pte. Ltd., Singapore) controlled by a programmable servo (Cornet COR 5/230, Elmo Motion Control Ltd., Israel) was used to drive the piston to generate pulsatile pressure waveforms. Function as mitral valve and aortic valve to 
Table 1 Diameters and length of vessels

\begin{tabular}{clll}
\hline & Segment Name & Diameter $\mathbf{( m m})$ & Length $\mathbf{( m m})$ \\
\hline ACA-A1 & Proximal Anterior Cerebral Artery & 2.5 & 20 \\
ACA-A2 & Distal Anterior Cerebral Artery & 3.0 & 250 \\
ACoA & Anterior Communicating Artery & 2.0 & 3 \\
BA & Basilar Artery & 5.0 & 30 \\
ICA & Internal Carotid Artery & 4.5 & 250 \\
PCA & Posterior Cerebral Artery & 3.0 & 250 \\
PCoA & Posterior Communicating Artery & 1.8 & 20 \\
VA & Vertebral Artery & 3.0 & 250 \\
\hline
\end{tabular}

prevent back flow, two one-way valves were connected to reservoir tank and compliance chamber, respectively. The effect of artery compliance was simulated by imposing an air chamber which air volume is adjustable. A flow distributor after the compliance chamber separated the flow into four branches and connected to the four afferent arteries of the CoW model.

A physiological pulsatile pressure waveform for the bilateral ICA and VA were applied as inlet boundary condition (Figure 3). The systolic pressure, diastolic pressure and average pressure are $16.1 \mathrm{kPa}(120.7 \mathrm{mmHg}), 10.97 \mathrm{kPa}(82 \mathrm{mmHg})$ and $12.7 \mathrm{kPa}$ (95 $\mathrm{mmHg}$ ), respectively $[44,45,53]$. The inlet pressure was measured by using dynamic pressure transducer (ATM231, Sensoren Transmitter Systeme GmbH, Sindelfingen, Germany). Six micro pressure transducers (XCQ-062, Kulite Semiconductor Products Inc., Ridgefield, NJ, USA) were installed at six bifurcation sites of the model, include the the bifurcation at the junction of bilateral PCA and PCoA, the bifurcation at the junction of bilateral MCA and PCoA and the bifurcation at the junction of bilateral ACA and ACoA. Pressure signals at these sites were recorded by a data acquisition system (Vision XP, LDS Test and Measurement GmbH, Ismaning, Germany).

Adjustable resistors were connected to the end of efferent arteries. Six beakers were placed at ends of the efferent arteries, and volume of fluid flows out from each efferent artery was measured periodically, to calculate the total mean volume flow rates and the flow rate of each efferent artery. The fluid collecting system simultaneously collected outflows from the CoW and distributes the fluid into six beakers so that the mean flow rate can be measured. The total flow rate of the complete CoW was set at physiological level of $760 \mathrm{ml} \cdot \mathrm{min}^{-1}$, and the flow rate ratio between VAs and ICAs was 30:70. The cardiac cycle was set to $0.8 \mathrm{~s}$ ( 75 beats $\left.\mathrm{min}^{-1}\right)$.

All devices were turned on 30 minutes before data collection for warm up and reach a stable condition. Measurements were collected for 100 consecutive cardiac cycles,
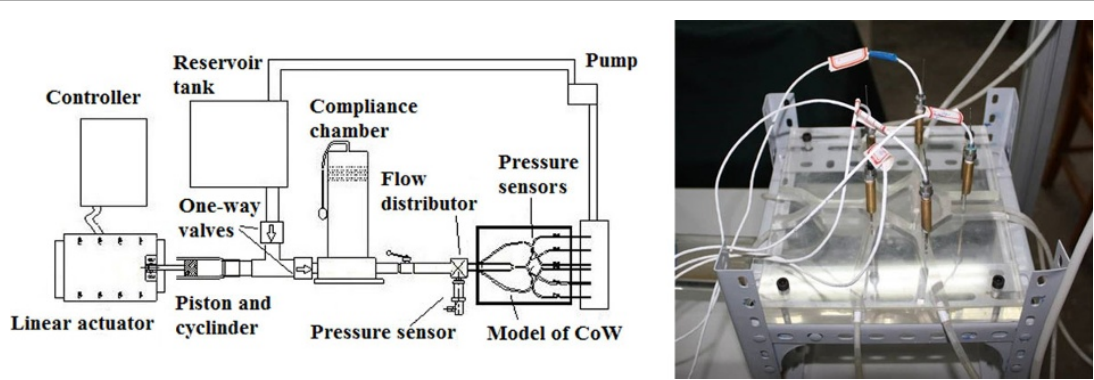

Figure 2 Schematic of experimental test rig. 


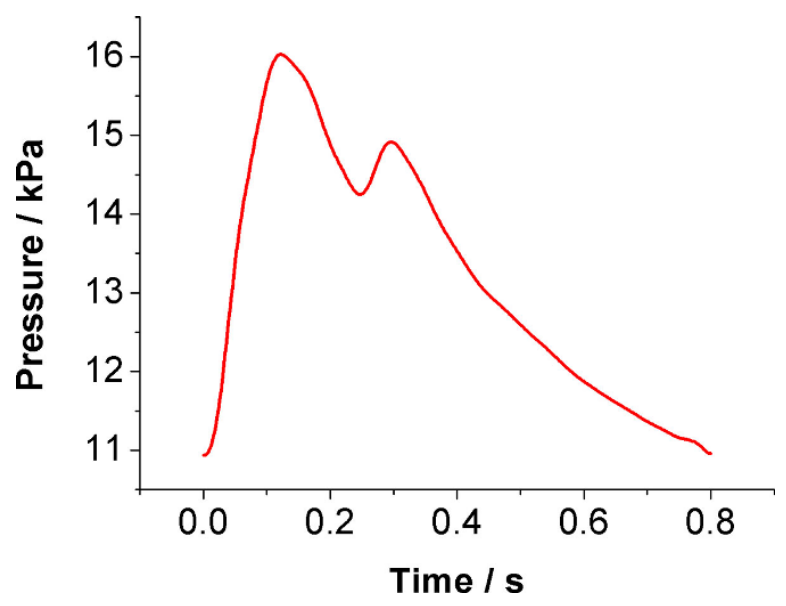

Figure 3 Inlet pressure waveform.

and were repeated three times for each cases mentioned above. In the complete CoW, the pressure waveforms measured over 100 cycles in L-ICA was within $0.1<\%$ for peak systolic pressure and peak diastolic pressure respectively, shows an excellent repeatability between cycles. The average pressure difference between L-ICA and R-ICA of the complete CoW at systolic peak is less than $0.8 \%$.

\section{Working fluid}

Blood is a non-Newtonian multiphase fluid with shear thinning properties. However, most researchers have considered blood as a Newtonian fluid except when they study the blood flow in medium to large arteries [54,55]. In this study, blood was assumed as Newtonian fluid. The working fluid applied here is a $40 \%$ aqueous solution of glycerin (volume ratio), the viscosity and density of which is $3.5 \mathrm{mPa} \cdot \mathrm{s}$ (DV-III+, Brookfield, USA) and $1056 \mathrm{~kg} \cdot \mathrm{m}^{-3}$, respectively.

\section{Experimental methods}

To investigate the blood flow distribution in the CoW under different ICA stenosis degrees, a series of pathological variations were considered, including:

1) Complete circle;

2) Different stenosis degrees of L-ICA (40\%, 50\%, 60\%, 75\%, and $87.5 \%)$ and L-ICA complete occlusion;

3) L-ICA occlusion coexist with the absence of communication arteries (R-PCoA, ACoA and L-PCoA).

Flow rates of above conditions were recorded and analysed.

To investigate the collateral mechanism of the CoW, pressure at both ends of each communicating artery (ACoA, L-PCoA and R-PCoA) under different L-ICA stenosis degrees was recorded, and this also provide indication of the flow direction.

\section{Results}

\section{Stenosis at L-ICA versus volume flow rate}

The total volume flow rates of CoW under different L-ICA stenosis degrees are illustrated in Figure 4. Detailed data were shown in Table 2. When a stenosis was introduced to the L-ICA, the total flow rate was directly affected. As the stenosis degree 


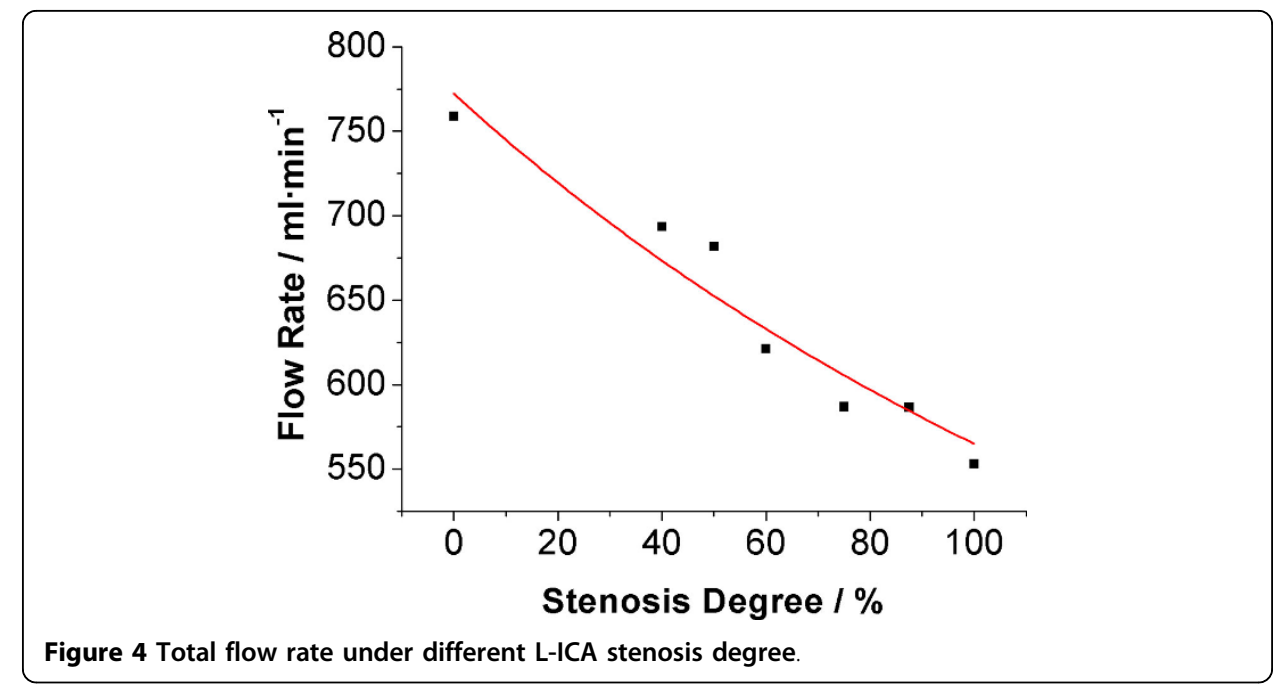

increased, the flow rate decreased continuously. When L-ICA was completely occluded, the total flow rate decreased by about $205 \mathrm{ml} \cdot \mathrm{min}^{-1}$. This is about $27 \%$ of the normal flow rate. In complete CoW, the distribution of flow to anterior, middle and posterior cerebral artery was accounts for $21.19 \%, 51.49 \%$ and $27.27 \%$ of total flow rate, respectively.

Figure 5 is a schematic illustrating the change of flow rates in efferent arteries (ACA, MCA and PCA) under different L-ICA stenosis degrees. The specific flow rates of efferent arteries are shown in Table 3.

There was an immediate reduction in blood flow through all of the efferent arteries when stenosis occurred, and the flow rates of all efferent arteries were decreased with the increasing of the stenosis degree of L-ICA. The three efferent arteries ipsilateral to the stenosis show the greatest relative reduction. When L-ICA was occluded, flow rate in the affected side of the ACA, MCA and PCA was $36.0 \%, 40.7 \%$ and $24.8 \%$ lower than normal conditions, respectively. The flow rate in the healthy side of the ACA, MCA and PCA was only $27.3 \%, 13.3 \%$ and $17.3 \%$ lower than normal conditions, respectively. This observation suggests that the L-MCA is affected most by the stenosis of L-ICA.

Under mild to medium degree of stenosis $(<50 \%)$, the volume flow rates in the ACA and PCA were decreased synchronously, and no obvious differences between bilateral branches were observed. When the stenosis degree is greater than $75 \%$, the result shows that the flow rates in bilateral ACA and PCA to become off-balance. This is an

Table 2 Total flow rates under different stenosis degree of L-ICA

\begin{tabular}{ccc}
\hline $\begin{array}{c}\text { Stenosis degree } \\
(\%)\end{array}$ & Total flow rate $\left(\mathbf{m l}^{\mathbf{m}} \mathbf{m i n}^{-\mathbf{1}}\right)$ & Percentage change (\%) \\
\hline 0 & 758.93 & 0 \\
40 & 693.58 & -8.61 \\
50 & 681.89 & -10.15 \\
60 & 621.32 & -18.13 \\
75 & 586.92 & -22.66 \\
87.5 & 585.56 & -22.84 \\
100 & 553.21 & -27.10 \\
\hline
\end{tabular}




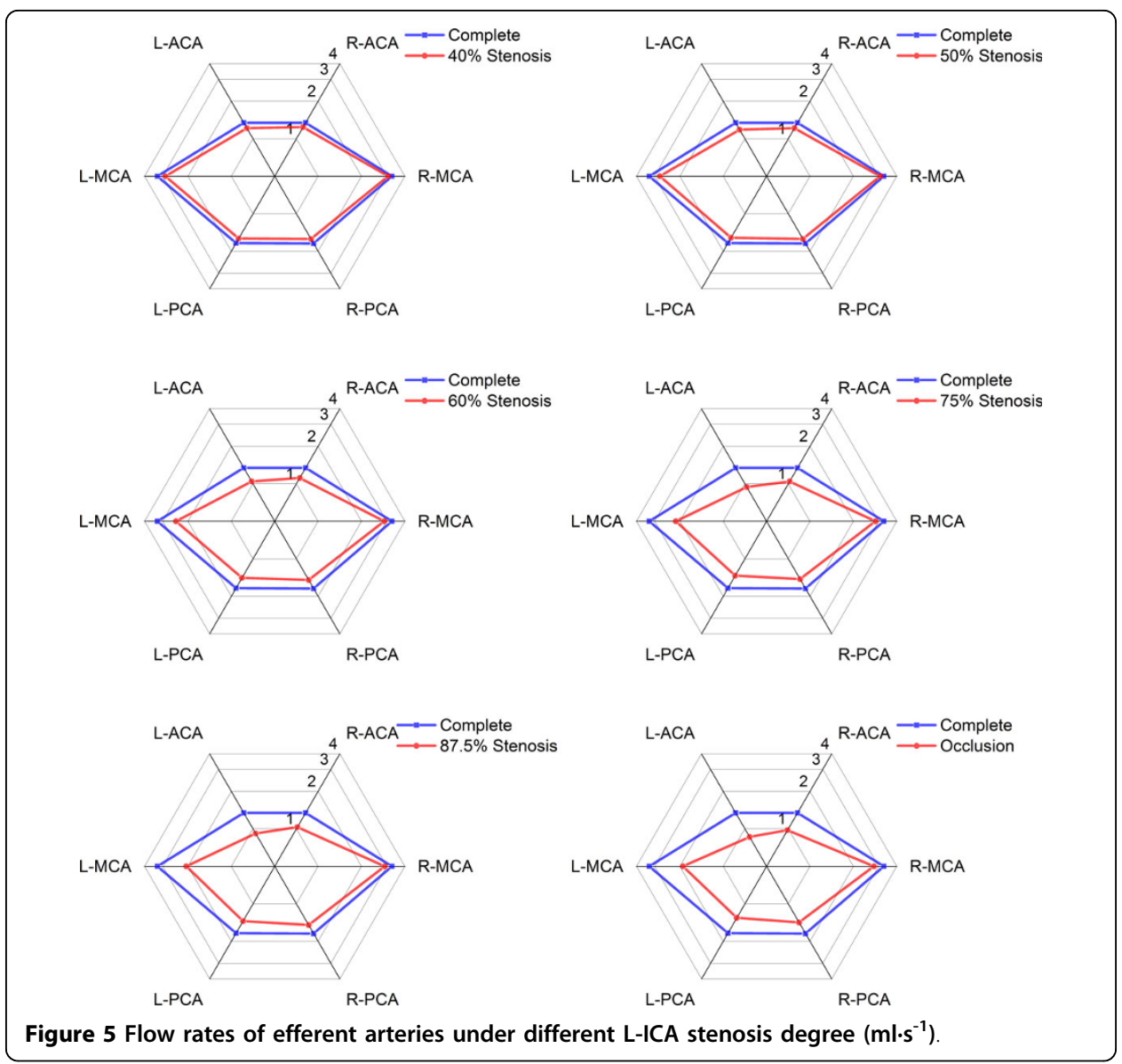

indication that the symmetry of the CoW is compromised. Compare with the ACA and PCA, the MCA is more sensitive to the morphology change of the ICA, see Table 3 and 4. The imbalanced flow between the bilateral MCA that appeared under mild stenosis and the difference in flow rates between the L-MCA and R-MCA increases continuously with the degree of stenosis.

The percentage change in flow rate of efferent arteries under different stenosis degree in Table 4 consistently shows the highest percentage change occurring in the L-MAC.

\section{Flow direction in communicating arteries}

To investigate the flow direction in communicating arteries, pressure signals were recorded at both ends of each communicating artery. Figure 6 shows the pressure difference between the upper end and lower end of L-PCoA and R-PCoA. Here, the upper end of $\mathrm{PCoA}$ is defined as the junction with $\mathrm{MCA}$, and the lower end is the junction with PCA; the pressure difference of PCoA is the pressure at the upper end minus the pressure at the lower end. When no stenosis occurred, the pressure difference at both ends of the PCoA is near zero. Blood from VAs and ICAs just supply their own perfusion area and there is no blood flow through the PCoA. The pressure difference at the L-PCoA is found decreased sharply when the L-ICA stenosis degree is greater than $40 \%$. This phenomenon can be explained as blood flow was drawing away 
Table 3 Flow rates of efferent arteries under different stenosis degree of L-ICA

\begin{tabular}{ccccccc}
\hline $\begin{array}{c}\text { Stenosis degree } \\
\text { (\%) }\end{array}$ & \multicolumn{7}{c}{ Flow rate in efferent arteries $\left(\mathbf{m l}^{-\mathbf{s}^{-1}}\right)$} \\
\cline { 2 - 7 } & R-ACA & R-MCA & R-PCA & L-PCA & L-MCA & L-ACA \\
\hline 0 & 1.34 & 3.26 & 1.73 & 1.72 & 3.26 & 1.34 \\
40 & 1.24 & 3.06 & 1.59 & 1.58 & 2.87 & 1.22 \\
50 & 1.22 & 3.06 & 1.59 & 1.56 & 2.75 & 1.18 \\
60 & 1.11 & 2.88 & 1.48 & 1.42 & 2.42 & 1.04 \\
75 & 1.04 & 2.84 & 1.46 & 1.36 & 2.13 & 0.94 \\
87.5 & 1.03 & 2.90 & 1.48 & 1.38 & 2.05 & 0.92 \\
100 & 0.97 & 2.78 & 1.41 & 1.30 & 1.90 & 0.86 \\
\hline
\end{tabular}

from the PCA, and flows from posterior to anterior. In contrast, contralateral PCoA is virtually unaffected, the pressure difference at R-PCoA increases slightly during the increase of L-ICA stenosis rate.

Figure 7 shows the pressure difference of $\mathrm{ACoA}$. This is the pressure at the right end of the ACoA minus the pressure at the left end of the ACoA. Under normal conditions, the pressure difference is near zero, which means no blood flow through ACoA. As the increase of L-ICA stenosis increases, the pressure difference also increases, the blood flow through ACoA from right to left.

\section{Flow distribution versus anatomical variations}

In addition to 1) the complete CoW and 2) L-ICA occlusion, three anatomical variations were also investigated:

3) L-ICA occlusion coexist with absence of contralateral PCoA,

4) L-ICA occlusion coexist with absence of ACoA,

5) L-ICA occlusion coexist with absence of ipsilateral PCoA.

The total volume flow rate of case (3) to (5) was 31.3\%, 31.3\%, 31.4\% lower than normal flow rate (case (1)) respectively, and about $7.1 \%$ lower than in case (2) where only occlusion occurred at the L-ICA (Figure 8).

The volume flow rates of efferent arteries are shown in Figure 9, detailed data are listed in Table 5. When contralateral PCoA absent, no obvious change of flow rate in efferent arteries were observed except R-PCA, which decreased $10 \%$ compare with case (2).

Absence of ACoA coexist with occlusion of L-ICA is the most critical situation to ipsilateral ACA among all cases investigated. The flow rate in ACA ipsilateral to

Table 4 Percentage change in flow rates of efferent arteries under different stenosis degree of L-ICA

\begin{tabular}{ccccccc}
\hline $\begin{array}{c}\text { Stenosis degree } \\
\text { (\%) }\end{array}$ & \multicolumn{7}{c}{ Percentage change in flow rate (\%) } \\
\cline { 2 - 7 } & R-ACA & R-MCA & R-PCA & L-PCA & L-MCA & L-ACA \\
\hline 0 & 0.00 & 0.00 & 0.00 & 0.00 & 0.00 & 0.00 \\
40 & -7.69 & -5.98 & -7.95 & -8.00 & -11.97 & -9.39 \\
50 & -9.39 & -5.98 & -7.95 & -9.33 & -15.49 & -11.96 \\
60 & -17.09 & -11.62 & -14.57 & -17.33 & -25.70 & -22.22 \\
75 & -22.22 & -12.68 & -15.89 & -20.66 & -34.51 & -29.91 \\
87.5 & -23.07 & -10.92 & -14.57 & -20.00 & -36.97 & -31.61 \\
100 & -27.34 & -14.79 & -18.55 & -24.67 & -41.55 & -35.89 \\
\hline
\end{tabular}



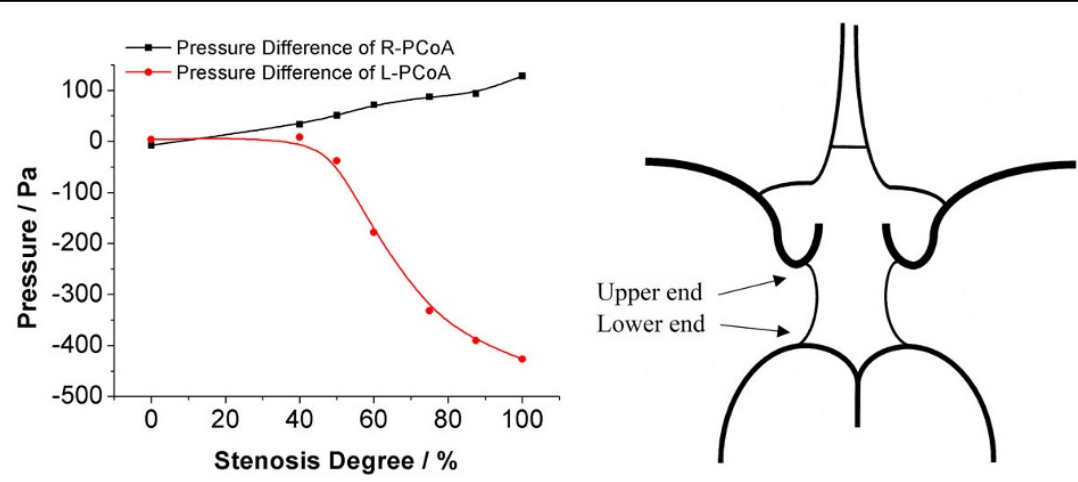

Figure 6 Pressure difference of PCoA.

L-ICA is $28.1 \%$ lower than that in case (2). The absence of ACoA also decreasing the flow through ipsilateral MCA, which is $21.5 \%$ lower compare with case (2). Meanwhile, flow rate of MCA and PCA contralateral to L-ICA have no significant change compare with case (2). Flow rate in contralateral ACA increased 18.6\% compare with case (2) and only $14.18 \%$ lower than complete CoW (case (1)).

In case (5), total CBF, flow rate in L-MCA and flow rate in R-ACA reached their lowest value compare with that of all cases. The flow rate in L-MCA and R-ACA is $23.43 \%$ and $9.28 \%$ lower than case (2), respectively. Flow rates in bilateral PCA are highest among case (2) to (5).

\section{Discussion}

In-vitro experimental study were carried out in present study to investigate the CBF distributions in efferent arteries, cross flow in communicating arteries and collateral circulation mechanism of the CoW. There are many factors that can influence the distributions of flow rates in the CoW. In the present study, neither the auto-regulation mechanism of peripheral arterial beds nor the vessel elastic was considered. As mentioned, the aim of this study is not to create a model of the CoW that can simulate all physiological factors of a real circulation system, but simply to investigate the impact

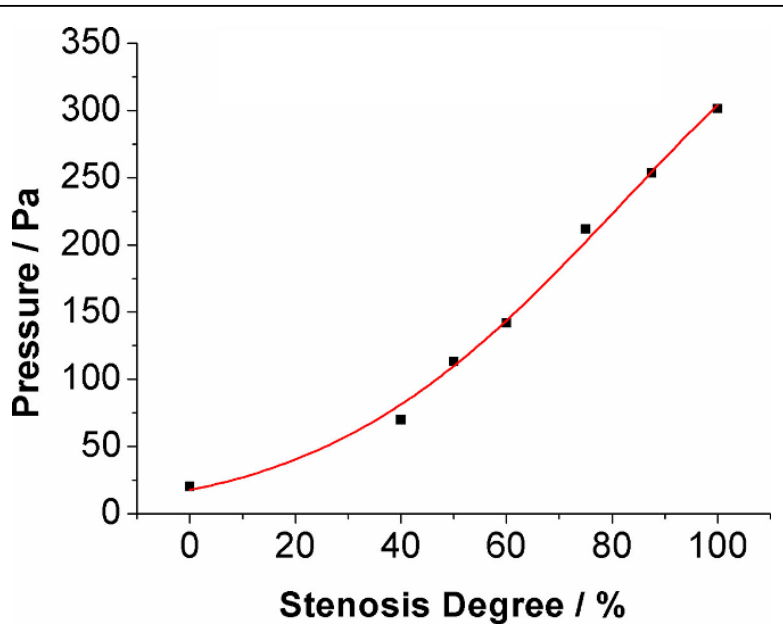

Figure 7 Pressure difference of ACoA. 


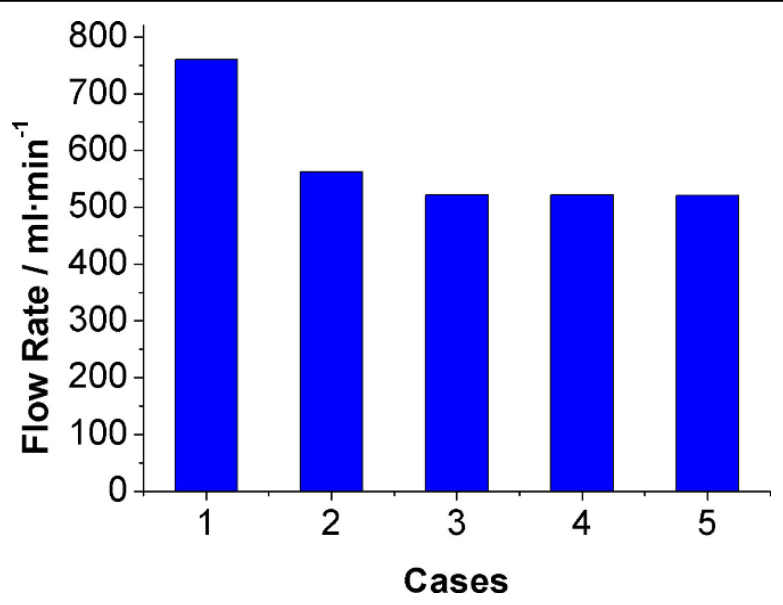

Figure 8 Total flow rates under different variations

of structural variation on the flow distribution in the CoW and the basic collateral circulation mechanism.

In developing the model of the CoW, validation is of the utmost importance if the model results are to be trusted. Due to the lack of clinical data that cover all cases studied in this paper, a comparison based on the complete CoW was considered. The flow rates of efferent arteries were compared between this study and previous clinical measurements.

Table 6 listed the results from phase-contrast MRI measurements.

The flow rates in ICAs and ACAs agree well with in-vivo measurements data. The flow rates in MCAs, BA and most noticeably the PCAs, however, appear to slightly larger than in-vivo measurements. According to the simplify of current model, this phenomenon could be explained as the absence of branch arteries of ICAs and BA, include the ophthalmic and anterior choroidal arteries, may cause the raise of flow

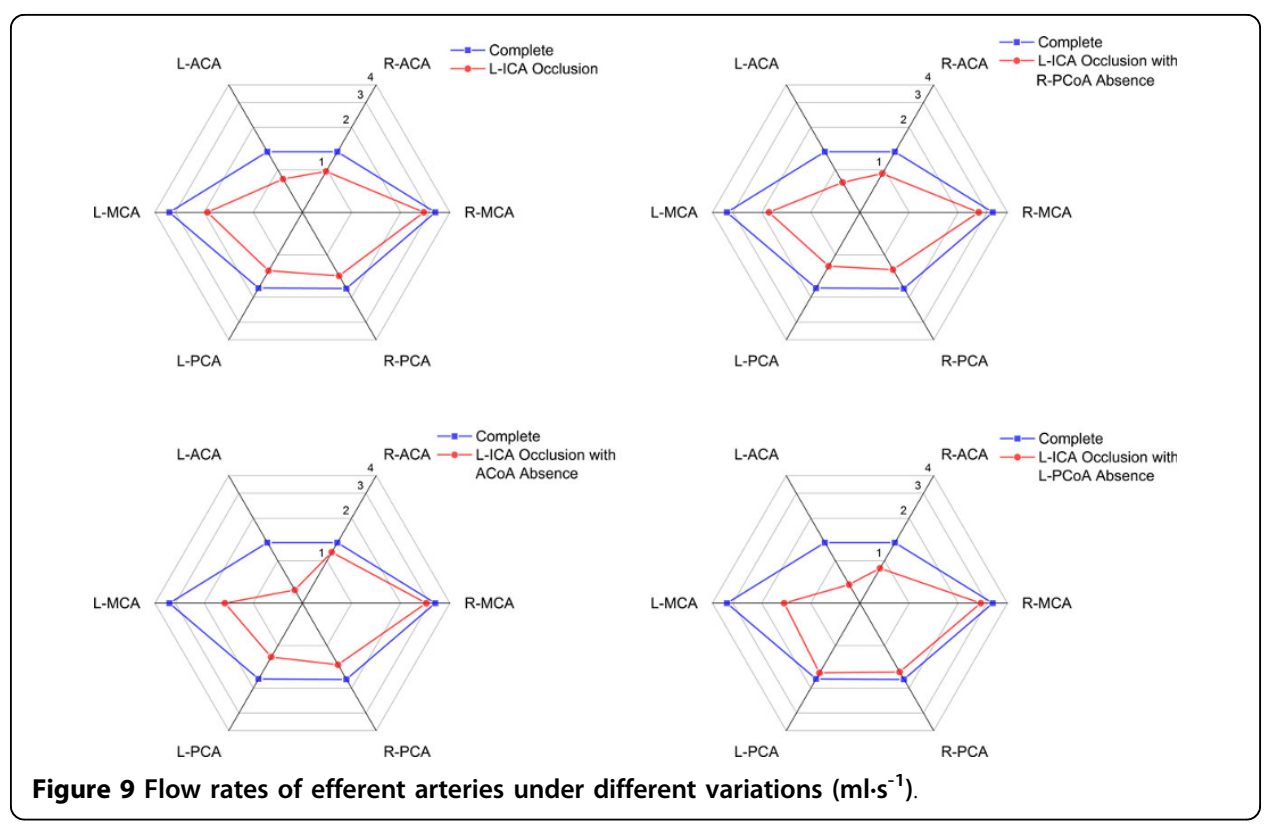


Table 5 Flow rates of efferent arteries under the absence of communicating arteries

\begin{tabular}{ccccccc}
\hline Case & \multicolumn{7}{c}{ Flow rate in efferent arteries $\left(\mathbf{m l} \cdot \mathbf{s}^{-\mathbf{1}}\right)$} \\
\cline { 2 - 7 } & R-ACA & R-MCA & R-PCA & L-PCA & L-MCA & L-ACA \\
\hline 1 & 1.34 & 3.26 & 1.73 & 1.72 & 3.26 & 1.34 \\
2 & 0.97 & 2.78 & 1.41 & 1.30 & 1.90 & 0.86 \\
3 & 0.94 & 2.67 & 1.27 & 1.20 & 1.80 & 0.81 \\
4 & 1.15 & 2.87 & 1.36 & 1.20 & 1.49 & 0.62 \\
5 & 0.88 & 2.75 & 1.54 & 1.56 & 1.45 & 0.68 \\
\hline
\end{tabular}

through MCAs and PCAs [47]. Further comparison was made between current results and previous numerical model [47] and in-vitro study [44], specific data were listed in Table 7.

These data presented in previous in-vivo, numerical and in-vitro studies are useful validations to show current in-vitro results are within acceptable physiological ranges. Therefore, the results in the study were convincing to provide information of CBF distribution and collateral circulation mechanism under such situations.

Notable decrease of flow rate in ACA and MCA was observed in the results, which indicate that the anterior circulation was affected most by ICA stenosis. When the stenosis degree of unilateral ICA increased from $0 \%$ to $100 \%$, the flow rate in ipsilateral ACA and MCA decreased $35.89 \%$ and $41.55 \%$ respectively. These values can be validated in the numerical study of Zhang et al [32]. Flow rates in PCA is less affected by unilateral ICA stenosis. This may due to the blood flow of posterior circulation are mainly provided by VA-BA system.

The pressure signal provides more information about the collateral compensation mechanism of the CoW. In complete CoW, the pressure difference between both ends of ACoA is almost zero, which indicated there is no blood flow through ACoA and the left and right circulation is relatively independent when the CoW is complete. This finding was in contrast to some numerical $[48,49]$ and in-vitro [45] studies, but it was in agreement other in-vitro [46], in-vivo [17] and numerical [30,47] studies. Uni-directional cross-flows occurs simultaneously in ACoA when stenosis induced to L-ICA. The blood flows through ACoA from the healthy side of the CoW to the affected side. As PCoA, the pressure difference of both PCoAs were near zero, which suggest there are almost no flow through PCoA in the complete CoW. When stenosis in unilateral ICA occurred, the pressure signals indicate that ipsilateral PCoA provides an important

Table 6 Comparison of flow rates of efferent arteries with previous in-vivo measurements

\begin{tabular}{|c|c|c|c|}
\hline \multirow[t]{2}{*}{ Study } & \multicolumn{3}{|c|}{ Volume flow rate $\left(\mathrm{ml}^{\left.-\mathrm{s}^{-1}\right)}\right.$} \\
\hline & ACAs & MCAs & PCAs \\
\hline $\begin{array}{l}\text { Current model } \\
\text { (Complete CoW) }\end{array}$ & 2.68 & 6.52 & 3.45 \\
\hline Enzmann et al. [57] & $2.72 \pm 0.35$ & $3.92 \pm 0.24$ & $1.73 \pm 0.14$ \\
\hline Ooij et al. [58] $]^{1, *}$ & $3.0 \pm 0.80$ & $6.2 \pm 1.60$ & $2.0 \pm 0.60$ \\
\hline Ooij et al. [58] $]^{2, *}$ & $3.0 \pm 0.80$ & $4.8 \pm 0.80$ & $2.0 \pm 0.60$ \\
\hline Zhao et al. [59] & $2.75 \pm 0.90$ & $4.92 \pm 0.97$ & $2.15 \pm 0.47$ \\
\hline
\end{tabular}

*The data provided in original paper was flow rates in unilateral arteries. For comparison, data presented here were doubled.

1. Results from $7 \mathrm{~T}$ scanning, $0.8 \mathrm{~mm}$ resolution

2. Results from 7T scanning, $0.5 \mathrm{~mm}$ resoulution 
Table 7 Comparison of flow rates of efferent arteries with previous numerical and in-vitro studies

\begin{tabular}{llll}
\hline Study & \multicolumn{3}{l}{ Volume flow rate $\left(\mathbf{m l} \cdot \mathbf{s}^{-1}\right)$} \\
\cline { 2 - 4 } & ACAs & MCAs & PCAs \\
\hline Current model & 2.68 & 6.52 & 3.45 \\
(Complete CoW) & & & 4.16 \\
Moore et al. [47] & 2.78 & 5.56 & 3.76 \\
Cieslicki et al. [44] & 3.1 & 4.85 &
\end{tabular}

collateral pathway in which the blood flow toward anterior circulation. This observation is supported by clinical TCD measurement [17]. The collateral compensation function of ipsilateral PCoA will be fully activated when the stenosis degree at L-ICA is greater than $40 \%$. Contralateral PCoA, however, only provides limited support to the compensation blood supply as the pressure difference is very small even L-ICA was complete occlude.

The role of PCoA and ACoA in collateral circulation was further revealed when take the anatomical variations into consideration. When the L-ICA occlusion coexist with the absence of ACoA, minimum flow rate in L-ACA was observed among all cases studied. This observation indicate that ACoA is an utmost important collateral path for ACA at affected side. For the whole anterior circulation and the total CBF supply, however, PCoA ipsilateral to stenosed ICA plays a more important role than ACoA in the collateral circulation. This conclusion is based on the observation that the flow rates in anterior circulation and the total $\mathrm{CBF}$ supply reached their minimum value when L-ICA occlusion coexist with the absence of ipsilateral PCoA. These observations are well agreed with clinical results [56].

This study had several limitations. Some vessels of the CoW, include ophthalmic artery, choroidal arteries and superior cerebellar arteries were simplified. As discussed before, the simplification would influence the flow distribution in the CoW. Moreover, flow visualization in current model is impossible. This drawback prevent us from access more detailed flow parameters, such as flow pattern and wall shear stress, which may help us have a further understanding of the hemodynamics of the CoW under different anatomical configurations. To access the wave propagation in the CoW, the vessel elasticity also need to be considered in future work.

\section{Conclusions}

Flow distribution patterns of the CoW under anatomical variations and the collateral mechanism of the CoW were investigated and clarified in present work. Experiment showed that PCoA is the most important collateral pathway in cerebral collateral circulation. The anatomical variation missing PCoA has the highest risk of TIA and cerebral stroke when the ipsilateral ICA has severe stenosis. In addition, the anterior circulation and posterior circulation of the CoW was found to be independent to each other until the ICA stenosis become severe. Moreover, we found that the collateral capacity of PCoA won't be fully activated until ICA stenosis degree is greater than $40 \%$. Further more, the results indicate that the flow in ACoA minght be used as a criterion of morphology change of ICA. These findings may potentially be used to enhance our understanding of the hemodynamics in the CoW and eventually lead to future therapeutic and diagnosis applications. 


\section{Competing interests}

The authors declare that they have no competing interests.

\section{Authors' contributions}

GYZ carried out the experimental study, participated in the sequence alignment and drafted the manuscript. QY participated in the design of this study and sequence alignment as supervisor. JY participated in the sequence alignment. JHY participated in the design of the study and helped to draft the manuscript.

\section{Acknowledgements}

This project is supported by Interdisciplinary Research Foundation of Xi'an Jiaotong University (XKJC2013013).

\section{Declarations}

Publication charges for this article have been funded by Interdisciplinary Research Foundation of Xi'an Jiaotong University (XKJC2013013).

This article has been published as part of BioMedical Engineering OnLine Volume 14 Supplement 1, 2015:

Cardiovascular Disease and Vulnerable Plaque Biomechanics. The full contents of the supplement are available online at http://www.biomedical-engineering-online.com/supplements/14/S1

\section{Authors' details}

${ }^{1}$ School of Energy and Power Engineering, Xi'an Jiaotong University, Xi'an, 710049, Shaanxi, China. ${ }^{2}$ Department of Radiology and Medical Imaging, the First Affiliated Hospital of Xi'an Jiaotong University, Xi'an, 710061, Shaanxi, China.

${ }^{3}$ School of Mechanical and Aerospace Engineering, Nanyang Technological University, Singapore, 639798, Singapore.

Published: 9 January 2015

\section{References}

1. Kluytmans M, van der Grond J, van Everdingen K, Klijn CJM, Kappelle LJ, Viergever Ma: Cerebral Hemodynamics in Relation to Patterns of Collateral Flow. Stroke 1999, 30:1432-1439.

2. Powers WJ: Cerebral hemodynamics in ischemic cerebrovascular disease. Ann Neurol 1991, 29:231-240.

3. Powers WJ, Press GA, Grubb RL, Gado M, Raichle ME: The effect of hemodynamically significant carotid artery disease on the hemodynamic status of the cerebral circulation. Ann Intern Med 1987, 106:27-34.

4. Schomer DF, Marks MP, Steinberg GK, Johnstone IM, Boothroyd DB, Ross MR, Pelc NJ, Enzmann DR: The anatomy of the posterior communicating artery as a risk factor for ischemic cerebral infarction. N Engl J Med 1994, 330:1565-1570.

5. Eftekhar B, Dadmehr M, Ansari S, Ghodsi M, Nazparvar B, Ketabchi E: Are the distributions of variations of circle of Willis different in different populations?-Results of an anatomical study and review of literature. BMC Neurol 2006, 6(22).

6. Amirjamshidi A, Mahmoodi R, Hashemi SM: Variations in the Anatomy of the Willis' circle: A 3-year cross-sectional study from Iran (2006-2009). Are the distributions of variations of circle of Willis different in different populations? Result of an anatomical study and review of literature. Surg Neurol Int 2013, 4:65.

7. Vrselja Z, Brkic H, Mrdenovic S, Radic R, Curic G: Function of circle of Willis. J Cereb Blood Flow Metab 2014, 34:578-584.

8. Lippert H, Pabst R: Arterial Variations in Man:classification and Frequency Munich: Springer; 1985.

9. Schneider PA, Ringelstein EB, Rossman ME, Dilley RB, Sobel DF, Otis SM, Bernstein EF: Importance of cerebral collateral pathways during carotid endarterectomy. Stroke 1988, 19:1328-1334.

10. Baumgartner RW: Intracranial stenoses and occlusions, and circle of willis collaterals. Front Neurol Neurosci 2006, 21:117-126.

11. Hoksbergen AWJ, Legemate DA, Csiba L, Csáti G, Siró P, Fülesdi B: Absent collateral function of the circle of Willis as risk factor for ischemic stroke. Cerebrovasc Dis 2003, 16:191-198.

12. Chaudhuri R, Padayachee TS, Lewis RR, Gosling RG, Cox TC: Non-invasive assessment of the Circle of Willis using transcranial pulsed Doppler ultrasound with angiographic correlation. Clin Radiol 1992, 46:193-197.

13. Hoksbergen AW, Legemate DA, Ubbink DT, Jacobs MJ: Collateral variations in circle of willis in atherosclerotic population assessed by means of transcranial color-coded duplex ultrasonography. Stroke 2000, 31:1656-1660

14. Hoksbergen AW, Legemate DA, Ubbink DT, de Vos HJ, Jacobs NJ: Influence of the collateral function of the circle of Willis on hemispherical perfusion during carotid occlusion as assessed by transcranial colour-coded duplex ultrasonography. Eur J Vasc Endovasc Surg 1999, 17:486-492.

15. Miralles M, Dolz JL, Cotillas J, Aldoma J, Santiso MA, Gimenez A, Capdevila A, Cairols MA: The role of the circle of Willis in carotid occlusion: Assessment with phase contrast MR angiography and transcranial duplex. Eur J Vasc Endovasc Surg 1995, 10:424-430.

16. Hoksbergen AW, Fülesdi B, Legemate DA, Csiba L: Collateral configuration of the circle of Willis: transcranial colorcoded duplex ultrasonography and comparison with postmortem anatomy. Stroke 2000, 31:1346-1351.

17. Hoksbergen AW, Majoie CBL, Hulsmans FJ, Legemate DA: Assessment of the collateral function of the circle of Willis: three-dimensional time-of-flight MR angiography compared with transcranial color-coded duplex sonography. AJNR Am J Neuroradiol 2003, 24:456-462.

18. Maltezos CK, Papanas N, Papas TT, Georgiadis GS, Dragoumanis CK, Marakis J, Maltezos E, Lazarides MK: Changes in blood flow of anterior and middle cerebral arteries following carotid endarterectomy: a transcranial Doppler study. Vasc Endovascular Surg 2007, 41:389-396.

19. Anzola GP, Gasparotti R, Magoni M, Prandini F: Transcranial Doppler Sonography and Magnetic Resonance Angiography in the Assessment of Collateral Hemispheric Flow in Patients With Carotid Artery Disease. Stroke 1995, 26:214-217. 
20. Muller M, Hermes M, Bruckmann H, Schimrigk K: Transcranial Doppler ultrasound in the evaluation of collateral blood flow in patients with internal carotid artery occlusion: correlation with cerebral angiography. AJNR Am J Neuroradiol 1995, 16:195-202.

21. Krabbe-Hartkamp M, Van der Grond J: Circle of Willis: morphologic variation on three-dimensional time-of-flight MR angiograms. Radiology 1998, 207:103-111.

22. Pennekamp CWA, van Laar PJ, Hendrikse J, den Ruijter HM, Bots ML, van der Worp HB, Kappelle LJ, Buhre WF, Bleys RLAW, Moll FL, de Borst GJ: Incompleteness of the circle of Willis is related to EEG-based shunting during carotid endarterectomy. Eur J Vasc Endovasc Surg 2013, 46:631-637.

23. Ito K, Sasaki M, Kobayashi M, Ogasawara K, Nishihara T, Takahashi T, Natori T, Uwano I, Yamashita F, Kudo K: Noninvasive Evaluation of Collateral Blood Flow through Circle of Willis in Cervical Carotid Stenosis Using Selective Magnetic Resonance Angiography. I Stroke Cerebrovasc Dis 2014, 23:1019-1023.

24. Shaban A, Albright KC, Boehme AK, Martin-Schild S: Circle of Willis Variants: Fetal PCA. Stroke Res Treat 2013, 2013:105937.

25. Cebral JR, Putman CM, Alley MT, Hope T, Bammer R, Calamante F: Hemodynamics in Normal Cerebral Arteries: Qualitative Comparison of 4D Phase-Contrast Magnetic Resonance and Image-Based Computational Fluid Dynamics. J Eng Math 2009, 64:367-378.

26. Ricci M, Cornacchiola V, Pigliautile M, Ercolani S, Mecocci P: Fetal variant of circle of the Willis and bilateral symmetrical parietal stroke. Neurol Sci 2012, 33:309-311.

27. Arjal RK, Zhu T, Zhou Y: The study of fetal-type posterior cerebral circulation on multislice CT angiography and its influence on cerebral ischemic strokes. Clin Imaging 2014, 38:221-225.

28. Mull M, Schwarz M, Thron A: Cerebral hemispheric low-flow infarcts in arterial occlusive disease. Lesion patterns and angiomorphological conditions. Stroke 1997, 28:118-123.

29. Bladin CF, Colchester ACF, Hawkes DJ, Seifalian AM, lqbal N, Hardingham CR: Morphological and Hemodynamic Assessments of Carotid Stenosis Using Quantitative Digital Subtraction Angiography. Stroke 1996, 27:1672-1678

30. Alastruey J, Parker KH, Peiró J, Byrd SM, Sherwin SJ: Modelling the circle of Willis to assess the effects of anatomical variations and occlusions on cerebral flows. J Biomech 2007, 40:1794-1805.

31. Moore SM, Moorhead KT, Chase JG, David T, Fink J: One-dimensional and three-dimensional models of cerebrovascular flow. J Biomech Eng 2005, 127:440-449.

32. Zhang C, Wang L, Li X, Li S, Pu F, Fan Y, Li D: Modeling the circle of Willis to assess the effect of anatomical variations on the development of unilateral internal carotid artery stenosis. Biomed Mater Eng 2014, 24:491-499.

33. DeVault K, Gremaud P, Novak V: Blood flow in the circle of Willis: Modeling and calibration. Multiscale Model Simul 2008, 7:888-909.

34. Grinberg L, Cheever E, Anor T, Madsen JR, Karniadakis GE: Modeling blood flow circulation in intracranial arterial networks: a comparative 3D/1D simulation study. Ann Biomed Eng 2011, 39:297-309.

35. Abdi M, Karimi A, Navidbakhsh M, Rahmati M, Hassani K, Razmkon A: Modeling the Circle of Willis Using Electrical Analogy Method under both Normal and Pathological Circumstances. J Biomed Phys Eng 2013, 3:45-56.

36. Cassot F, Zagzoule M, Marc-Vergnes JP: Hemodynamic role of the circle of Willis in stenoses of internal carotid arteries. An analytical solution of a linear model. J Biomech 2000, 33:395-405.

37. Ferrandez A, David T, Brown MD: Numerical models of auto-regulation and blood flow in the cerebral circulation. Comput Methods Biomech Biomed Engin 2002, 5:7-19.

38. Ferrández A, David T, Bamford J, Scott J, Guthrie A: Computational Models of Blood Flow in the Circle of Willis. Comput Methods Biomech Biomed Engin 2000, 4:1-26.

39. Long Q, Luppi L, König CS, Rinaldo V, Das SK: Study of the collateral capacity of the circle of Willis of patients with severe carotid artery stenosis by 3D computational modeling. J Biomech 2008, 41:2735-2742.

40. Reorowicz P, Obidowski D, Klosinski P, Szubert W, Stefanczyk L, Jozwik K: Numerical simulations of the blood flow in the patient-specific arterial cerebral circle region. J Biomech 2014, 47:1642-1651.

41. Oshima M, Torii R, Tokuda S, Yamada S, Koizumi A: Patient-Specific Modeling and Multi-Scale Blood Simulation for Computational Hemodynamic Study on the Human Cerebrovascular System. Curr Pharm Biotechnol 2012, 13:2153-2165.

42. Alnaes MS, Isaksen J, Mardal KA, Romner B, Morgan MK, Ingebrigtsen T: Computation of hemodynamics in the circle of Willis. Stroke 2007, 38:2500-2505.

43. Cebral JR, Castro MA, Soto O, Löhner R, Alperin N: Blood-flow models of the circle of Willis from magnetic resonance data. J Eng Math 2003, 47:369-386.

44. Cieslicki K, Ciesla D: Investigations of flow and pressure distributions in physical model of the circle of Willis. J Biomech 2005, 38:2302-2310

45. Fahy $\mathrm{P}, \mathrm{McC}$ arthy $\mathrm{P}$, Sultan $\mathrm{S}$, Hynes $\mathrm{N}$, Delassus $\mathrm{P}$, Morris $\mathrm{L}$ : An experimental investigation of the hemodynamic variations due to aplastic vessels within three-dimensional phantom models of the circle of Willis. Ann Biomed Eng 2014, 42:123-138.

46. Ujiie H, Liepsch DW, Goetz M, Yamaguchi R, Yonetani H, Takakura K: Hemodynamic study of the anterior communicating artery. Stroke 1996, 27:2086-2093, discussion 2094.

47. Moore S, David T, Chase JG, Arnold J, Fink J: 3D models of blood flow in the cerebral vasculature. J Biomech 2006, 39:1454-1463.

48. Alastruey J, Parker KH, Peiró J, Byrd SM, Sherwin SJ: Modelling the circle of Willis to assess the effects of anatomical variations and occlusions on cerebral flows. J Biomech 2007, 40:1794-1805.

49. Jou LD, Lee DH, Mawad ME: Cross-flow at the anterior communicating artery and its implication in cerebral aneurysm formation. J Biomech 2010, 43:2189-2195.

50. Hartkamp MJ, van der Grond J, van Everdingen KJ, Hillen B, Mali WPTM: Circle of Willis Collateral Flow Investigated by Magnetic Resonance Angiography. Stroke 1999, 30:2671-2678.

51. Hendrikse J, van Raamt a F, van der Graaf Y, Mali WPTM, van der Grond J: Distribution of cerebral blood flow in the circle of Willis. Radiology 2005, 235:184-189.

52. Hillen $B$, Gaasbeek T, Hoogstraten HW: A mathematical model of the flow in the posterior communicating arteries. J Biomech 1982, 15:441-448. 
53. Van de Vosse FN, Stergiopulos N: Pulse Wave Propagation in the Arterial Tree. Annu Rev Fluid Mech 2011, 43:467-499.

54. Steinman DA, Ethier CR: The effect of wall distensibility on flow in a two-dimensional end-to-side anastomosis. J Biomech Eng 1994, 116:294-301.

55. Xu XY, Collins MW, Jones CJ: Flow studies in canine artery bifurcations using a numerical simulation method. J Biomech Eng 1992, 114:504-511.

56. Liebeskind DS: Collateral circulation. Stroke 2003, 34:2279-2284.

57. Enzmann DR, Ross MR, Marks MP, Pelc NJ: Blood flow in major cerebral arteries measured by phase-contrast cine MR. AJNR Am J Neuroradiol 1994, 15:123-129.

58. Van Ooij P, Zwanenburg JJM, Visser F, Majoie CB, Hendrikse J, Nederveen AJ: Quantification and Visualization of Flow in the Circle of Willis: Time-Resolved Three-Dimensional Phase Contrast MRI at 7 T Compared with 3 T. Magn Reson Med 2013, 69:868-876.

59. Zhao M, Amin-Hanjani S, Ruland S, Curcio AP, Ostergren L, Charbel FT: Regional Cerebral Blood Flow Using Quantitative MR Angiography. Am J Neuroradiol 2007, 28:1470-1473.

doi:10.1186/1475-925X-14-S1-S10

Cite this article as: Zhu et al:: Experimental study of hemodynamics in the circle of willis. BioMedical Engineering

OnLine 2015 14(Suppl 1):S10.

Submit your next manuscript to BioMed Central and take full advantage of:

- Convenient online submission

- Thorough peer review

- No space constraints or color figure charges

- Immediate publication on acceptance

- Inclusion in PubMed, CAS, Scopus and Google Scholar

- Research which is freely available for redistribution 